\title{
Reflections on the Virtual 32nd NIDCAP Trainers Meeting 20 - 22 October 2021
}

\author{
Attendance at a NIDCAP Trainers Meeting provides us with the opportunity to hear new \\ ideas and learn from our colleagues. Below we have three unique perspectives of the
} meeting from Members of the NFI.

\section{Jacques Sizun, MD}

\section{Centre Hospitalier Universitaire de Toulouse| CHU Toulouse Service de Néonatologie}

During the 32nd Annual NIDCAP trainers Meeting, Sari Goldstein Ferber, PhD, from Bar Ilan University, Israel, presented an interesting reflection on the potential impact of NIDCAP on the homeostatic regulation of hypothalamic (HPA) axes. She presented three axes that are regulated by melatonin, cortisol and oxytocin. They play important roles in the maturation of circadian rhythms, the modulation of stress, and the relationship and bonding. The behavioral observations using the Synactive Theory framework are focused on the management of the wake/sleep states, and on the permanent balance (and imbalance) of the stress-induced behaviors. The baby's strategies for self-regulation and the co-regulation by parents are important to manage stress behaviors. Recommendations are always oriented toward attachment and bonding support.

This presentation could have three impacts:

- The first impact is on my own vision of the newborn, their development and care. It is very important not to stay in our "ivory tower", being too comfortable and secure can isolate us from the outside world. Confronting our own theoretical models with advances in science and medicine is an exercise that is sometimes intellectually difficult but very nurturing.

- The second impact concerns our healthcare professional colleagues who may not be convinced by our approach to care. The psychoneuroendocrine perspective can be a gateway to NIDCAP for them, as it has been observed for other fields of newborn care such as: pain (close link between developmental care practices and non-pharmacological treatments); palliative care (same philosophy of holistic, individualized, family-centered care); and/or breastfeeding support.

- The third impact could be for research. Using tools from other fields of clinical research to explore the impact of NIDCAP appears exciting.

Conclusion: Connection is essential!

\section{Jim Helm, PhD}

\section{Director Emeritus, Carolina NIDCAP Training Center}

When I attend a conference, and in particular, the NIDCAP Trainers Meeting, I hope to be re-energized around the mission and goals of the NIDCAP approach and... to see old friends who have shared goals; to learn about new ideas, research and applications; and to be inspired. This day did not disappoint me, rather it brought energy, reflection and the hard-to-come-by inspiration.

The Pearls of Wisdom segments of the meeting have members sharing personal experiences that have helped shape their caring and offer participants a unique opportunity to join a colleague's personal perspective. Andrea Nykipilo, RN and gretchen Lawhon, PhD, RN, FAAN provided a wonderful start to the day with thoughts on how the NIDCAP approach has opened one to be in the moment and how learning imparts a sense of duty to teach others. Perfect for NIDCAP work.

Dr Als' keynote address built from that setting-of-thestage as she embraced the meeting's theme - Always Together - and examined it from within the uncertainties and cautiousness of the pandemic. Discussing the critical importance of "being together" during critical times, whether during a pandemic or negotiating the challenges of being admitted to an NICU. No matter, human togetherness is supportive, facilitates growth, development and healing and especially for the fragile infants and traumatized families of the NICU.

The NFI Membership Meeting, presided over by Deborah Buehler, PhD, President of the NFI Board of Directors also had such a positive vibe as examples of the many pockets of growth were provided where the NIDCAP approach is understood, valued, and promoted. NFI members need to find and read the committee reports. In our daily lives we can easily lose the "big picture" of growth around the world. This meeting helps us reconnect.

Clinical Practice and Abstract presentations showed strong examples of affecting change in systematic ways be it a specific care practice (Four-handed care: L. Eitan) or a unit culture shift as we saw in the beautiful photo presentation from Sweden (Continuous skin-to-skin contact: S Klemming). The 


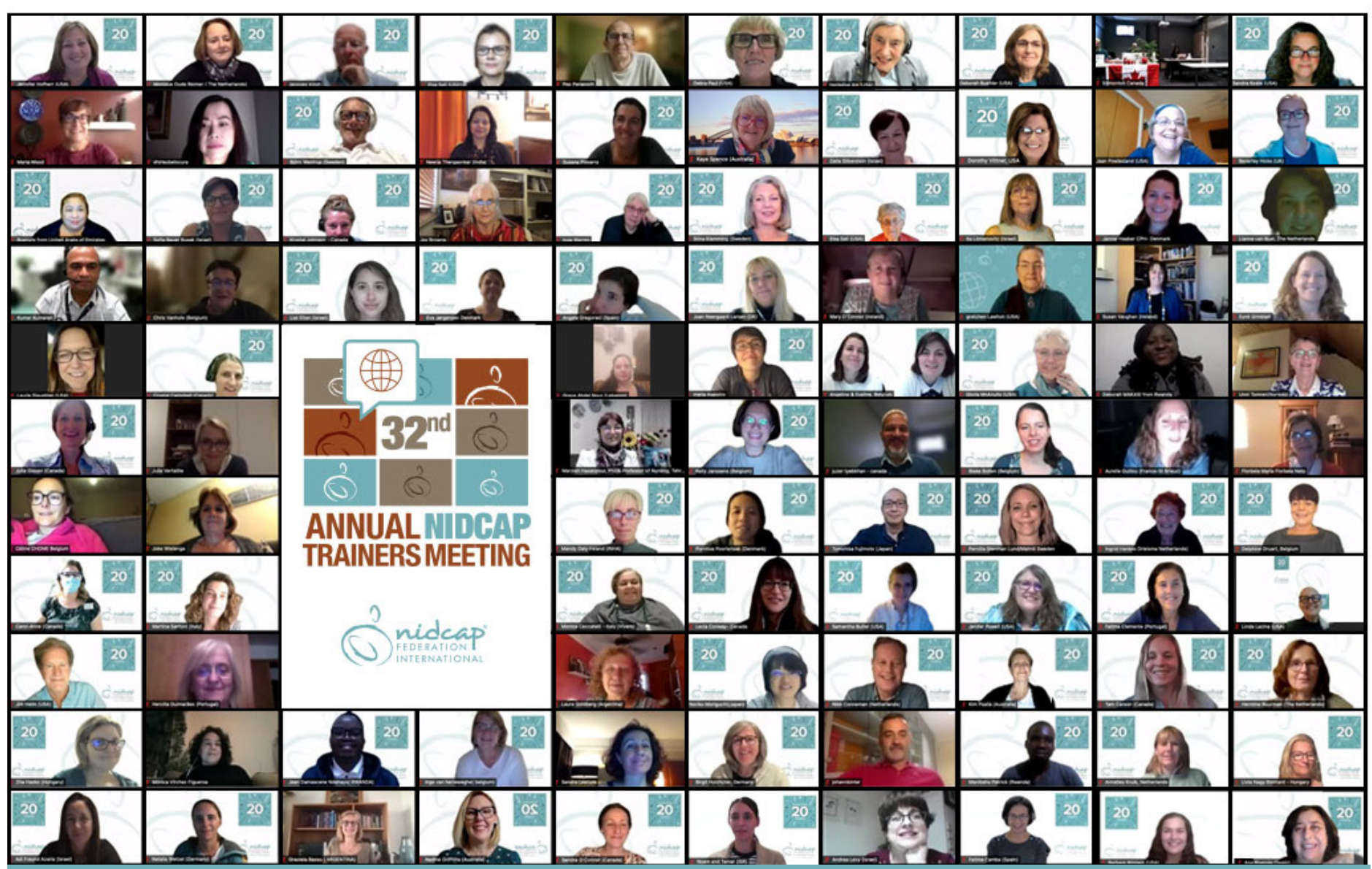

Some of the 124 attendees from 23 countries present for the Virtual NIDCAP Trainers Meeting.

abstracts featured efforts to support families in their challenge to parent in the NICU and as NICU supports are removed, through the transition to home.

The Journal Club, a fairly new component of meetings that has taken hold, brings us new ideas. This segment gave us two articles to share and discuss. Generation Z, as with each new family, will challenge us to accept families, individuals, as they are, and adapt. The bio-ecology of behavior and behavior change offers new insights as to how we understand change and perhaps a way to measure differences in change.

A day full of thoughtful perspectives on change. May they inspire and challenge our next year as we work together.

\section{Mandy Daly}

\section{NFI Board Member, Founder of the Irish Neonatal Health Alliance}

Preterm birth flips the paradigm of parenthood on its axis and robs families of their hopes, dreams and expectations. A preterm birth is often preceded by a rocky and tumultuous pregnancy journey and can culminate in an emergency birth situation that is fraught with urgency, fear and uncertainty. A full-term healthy pregnancy, a natural birth, those precious first moments when Mum meets baby, babies first outside of the womb sensory experience skin to skin with Mum, hearing her voice and smelling her scent are replaced by clinical handling by strangers, pain as airways are cleared and lines inserted, and fear and confusion.

When a newborn requires care in the Neonatal Unit families are forced to re-evaluate their anticipated parenting role and as if being separated from one's baby at birth is not traumatic enough, families are burdened further by having to learn the language of the neonatal unit, shelve their own need to recover physically and emotionally from the traumas of the pregnancy and delivery and find a way to parent their sick and vulnerable infant in an environment that excels at erecting barriers.

Research has demonstrated that the relationship that a baby has with their parent or primary carer, has an enormous impact on their future mental, physical, social, and emotional health. The neonatal period is critical to the development of the parent-child relationship. In fact, the strength of this relationship is the main predictor of how well a child will do both in school and in life. It is not founded on the quality of the care 
or parental love, but on the non-verbal emotional communication that a parent develops with their child, known as the attachment bond.

Experience shapes the brain and having an infant in the neonatal unit has the potential to erode the fundamental and foundational natural connections; the consequences of which, if unaddressed can be detrimental for the infant and the family unit. Families are the cornerstone upon which newborn care must be developed and delivered. It is imperative that newborn care practices embody the essence of connecting families and strive to repair the fractured connections at every juncture. The NIDCAP approach to care acknowledges the important role that families play in their baby's development, it recognizes the infant's need for positive familial and sensory experiences to support his/her developing competencies and it facilitates connections at every step of the journey by protecting the developing infant brain and the evolving infant parent relationship.

The COVID-19 global pandemic has brought unimaginable challenges for newborn healthcare systems and families, but never has it been more important to remain steadfast in keeping babies and their families together. On the first day of the NFI Trainers Meeting, Dr. Manuela Filippa's presentation about her unit's family-based intervention that focuses on the benefits of early vocal contact between parents and preterm infants, struck a chord close to my heart. Having spent over three months in a neonatal unit with my daughter many years ago, at a time when parents were still considered "visitors" on the unit, and seeing 15 years of advocating for family and infant centered developmentally supportive care to be embedded at the heart of care pathways, wiped out over-night in many NICUs around the world by the pandemic, it was encouraging to see the positive results from initiatives such as Manuela's. We need to see more neonatal units adapt their practices to reflect positive research findings and researchers need to explore more opportunities that embed families at the heart of neonatal care.

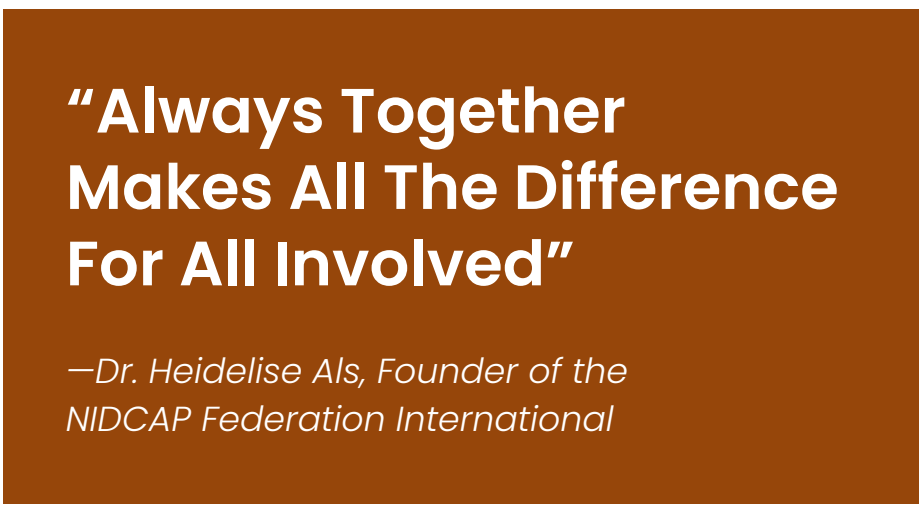

\section{Advertising in the Developmental Observer}

\section{The benefits of sponsoring the Developmental Observer include:}

" Distribution and reach to the 250 members of the $\mathrm{NFI}$, plus an additional 300 people receiving NFI news

" Potential reach to thousands of readers of the Developmental Observer via the NFI website and multiple social media platforms

" Developmental Observer is indexed through Scholar Works, EBSCO (US based library database abstract and indexing service) and Google Scholar.

" Sponsor information available to key health care professionals and policy developers for newborn care

For more information on how to sponsor the Developmental Observer and promote your activity, meeting or company please contact info@nidcap.org. We offer three levels of Corporate sponsor rates as well as Institution/ Organization rates.

\section{(Continued from p. 11)}

References:

1. Graven SN, Browne J V. Sensory development in the fetus, neonate, and infant: Introduction and overview. Newborn Infant Nurs Rev 2008; 8: 169-172. DOI:10.1053/J. NAINR.2008.10.007

2. Bieleninik $€$, Ghetti C, Gold C. Music therapy for preterm infants and their parents: A meta-analysis. Pediatrics 2016; 138 (8): e20160971. doi: 10.1542/peds.2016-0971

3. Arnon S, Diamant C, Bauer S, et al. Maternal singing during kangaroo care led to autonomic stability in preterm infants and reduced maternal anxiety. Acta Paediatr Int $J$ Paediatr 2014; 103: 1039-1044. doi: 10.1111/apa.12744

4. Haslbeck, Friederike; Hugoson, Pernilla (2017). Sounding Together: Family-Centered Music Therapy as Facilitator for Parental Singing During Skin-to-Skin Contact. In: Filippa, Manuela; Kuhn, Pierre; Westrup, Björn. Early vocal contact and preterm infant brain development: bridging the gaps between research and practice. Cham: Springer, 217-238 doi.org/10.1007/978-3-319-65077-7_13

5. Cresswell JW. Research Design - Qualitative, Quantitative and Mixed Methods. 3rd Edition. 2009. Sage Publications, Los Angeles. https://www.ucg.ac.me/skladiste/ blog_609332/objava_105202/fajlovi/Creswell.pdf

6. Loewy J, Stewart K, Dassler A-M, et al. The Effects of Music Therapy on Vital Signs, Feeding, and Sleep in Premature Infants. Pediatrics 2013; 131: 902 LP - 918. doi: 10.1542/ peds.2012-1367

7. Longin E, Gerstner T, Schaible T, et al. Maturation of the autonomic nervous system: differences in heart rate variability in premature vs. term infants. J Perinat Med, 2006;34(4):303-8.doi: 10.1515/JPM.2006.058

8. Westrup B. Newborn Individualized Developmental Care and Assessment Program (NIDCAP) - Family-centered developmentally supportive care. Early Hum Dev 2007; 83: 443-449. doi: 10.1016/j.earlhumdev.2007.03.006 